\title{
SIMULATION-BASED ROBUST OPTIMIZATION FOR COMPLEX TRUCK-SHOVEL SYSTEMS IN SURFACE COAL MINES
}

\author{
Sai Srinivas Nageshwaraniyer \\ Young-Jun Son \\ Systems and Industrial Engineering \\ The University of Arizona \\ Tucson, AZ 85721, USA
}

\author{
Sean Dessureault \\ Mining and Geological Engineering \\ The University of Arizona \\ Tucson, AZ 85721, USA
}

\begin{abstract}
A robust simulation-based optimization approach is proposed for truck-shovel systems in surface coal mines to maximize the expected value of revenue obtained from customer trains. To this end, a large surface coal mine in North America is considered as case study, and a highly detailed simulation model of that mine is constructed in Arena. Factors encountered in material handling operations that may affect the robustness of revenue are then classified into 1) controllable, 2) uncontrollable and 3) constant categories. Historical production data of the mine is used to derive probability distributions for the uncontrollable factors. Then, Response Surface Methodology is applied to derive an expression for the variance of revenue under the influence of controllable and uncontrollable factors. The resulting variance expression is applied as a constraint to the mathematical formulation for optimization using OptQuest. Finally, coal production is observed under variation in number of trucks and down events.
\end{abstract}

\section{INTRODUCTION}

Today, coal is one of the leading sources of energy production in the U.S. In 2011, it was the second highest source of energy production behind natural gas at 22.18 quadrillion BTUs in the U.S (U.S. Energy Information Administration 2012). In order to sustain coal production at a high level to continue to support the nation's economy, it is important that the coal production be economically viable. Thus, it is important for mines to maximize revenues obtained by delivery of coal and minimize costs associated with coal production. In this work, it is aimed to maximize revenue obtained from each customer at surface coal mines, where trucks, shovel and dumps are the major equipment. Previously, mathematical programming formulations and simulation-based optimization methods (Nageshwaraniyer, Son, and Dessureault 2013a) have been proposed for coal blending optimization to maximize revenue. Among them, due to the complexity involved in complex truck-shovel-dump systems to estimate tonnage produced in any time period, simulation based methods provide relatively more accurate estimates of truck-shovel-dump operational settings to maximize revenue (Smart Simulation Blog 2012). In addition, the presence of large number of uncertain parameters in the revenue maximization problem necessitates the finding of robust optimal solutions. Robust optimization in deterministic and stochastic programming contexts has been widely researched in literature. By taking set-based uncertainty as focus, methods to address them in integer, non-linear and linear programming formulations with closed-form expressions have been addressed in Bertsimas (2011). Similarly, Sahinidis (2004) discusses different types of uncertainties arising in optimization formulations, and stochastic programming methods to address them. Since simulationbased optimization involves non-closed form formulations, stochastic and deterministic programming methods for robust optimization cannot be applied directly. Also, the uncertainty set of parameters 


\section{Nageshwaraniyer, Son, and Dessureault}

of interest is large in simulation models in comparison to those in stochastic programming formulations (Fu 2002). So, the simulation outputs and their variances are estimated either through a different means such as using large numbers of controlled simulation runs or using a metamodel of the simulation model (Dellino, Kleijnen, and Meloni 2009). In Dellino, Kleijnen, and Meloni (2012), Response Surface Methodology (RSM) was applied for simulation model and in Dellino, Kleijnen, and Meloni (2009), both RSM and Kriging metamodels were applied. Later, Dellino, Kleijnen, and Meloni (2012) used Kriging metamodel to first estimate and then maximize the expected value of objective function, while minimizing its variance as a constraint using mathematical programming methods. The reader is referred to Neddermeijer et al. (2000), Ramberg et al. (1991) and Barton and Meckesheimer (2006) for applications of RSM to simulation modeling and optimization. In this work, a method similar to the one in Dellino, Kleijnen, and Meloni (2009) is used, where RSM is applied to determine the variance expression of the objective function under different simulation model parameter settings. However, since the simulation model of interest is complex, the obtained variance expression is applied as constraint to formulation in OptQuest to obtain robust solutions. This is different from Dellino, Kleijnen, and Meloni (2009), where a mathematical programming method was applied to optimize the metamodel of the simulation model subject to obtained variance. To the best knowledge of authors of this paper, for simulation-based optimization with discrete decision variables, this is one of the first attempts on applying prior information about variance of solutions to guide the optimization heuristic towards solution with least variance. This is implemented by applying RSM to obtain an expression for variance of simulation output, which is then applied in OptQuest as a constraint to arrive at the solution with not only the largest expected value of revenue but least variance as well.

In a real mine, coal is loaded onto trucks by shovels, which then haul coal and dump it into dumps. Coal is then conveyed to large inventories called silos from where coal is pulled via conveyors and loaded onto trains. All these coal-handling operations in the mine are concerned in the simulation model in this work along with maintenance events affecting trucks, shovels and hoppers. While controllable factors include numbers of trucks, shovels and hoppers, truck locks, and customer quality specifications, uncontrollable factors include mean time between failures (MTBF) and mean time to repair (MTTR) for trucks, shovels and hoppers, truck haul times, and shovel loading and truck-dumping rates. The constants that do not affect revenue are numbers of silos, conveyors and loadouts along with conveyor settings. More specifically, the procedure involves 1) first order effects for controllable factors, 2) first order effects for uncontrollable factors, and 3) two factor interactions between controllable and uncontrollable factors. The unknown parameters in the RSM metamodel are estimated by converting the metamodel into a linear regression model, obtaining outputs from simulation runs and then using least squares method. The resulting metamodel is validated for various factor settings using leave-one-out cross validation, and is then applied as an additional constraint to the mathematical formulation to obtain the robust maximum revenue in the simulation model using OptQuest. OptQuest is an optimization add-on for several commercial simulation software (Arena is used in this work) that uses Tabu search, Scatter search, and neural network algorithms to arrive at the optimal solution. The decision variables in this formulation are truck locks only. Revenue is a function of the actual quality of coal delivered to each customer and their corresponding quality specifications for premiums and penalties. The upper bound on the variance as a constraint is varied to obtain different sets of expected value as well as variances of revenue. The data warehouse is implemented in Microsoft SQL (Structured Query Language) Server, and contains snapshots of historical data production outputs and equipment statuses at regular intervals in each shift of the mine. The proposed procedure was tested at the control room situated in the Mining and Geological Engineering Department at the University of Arizona, shown in Figure 1. This is a model dispatch control room for large surface mines around the world. It contains multiple monitors and desktops that are connected to the data warehouse at the mine under case study. They are also connected to a copy of the data warehouse located at the University. The purpose of conducting experiments in this room is to tailor the procedure to improve its usability for end-users who are truck dispatchers at the real mine. 
A brief description on the remaining sections in this paper is given in this paragraph. Details of the case study, including the material handling operations from loading of trucks by shovels to loading of customer trains at loadouts is given in Section 2. Then the mathematical formulation of robust revenue maximization problem is provided in Section 3. In Section 4, details of the experimental setup are provided along with description of an Arena simulation model of material handling network of the mine under focus and the associated user interface in Microsoft Excel. Experimental results are also discussed in the same section. Conclusions of this paper are drawn in Section 5, and future works by the authors are also mentioned.

\section{CASE STUDY}

In this paper, one of the largest surface coal mines in North America is considered for case study. The mine is operational throughout the year. Each day at the mine is divided into two shifts. About 12 customer trains arrive at the mine in each shift. There are different material handling equipment in the mine to load coal onto customer trains. They are trucks, shovels, dumps, over land conveyors, silos, blending conveyors and loadouts (Figure 2). Dumps are also known as hoppers or crushers. The coal loading process observed at the mine is as follows: shovels excavate coal and load them onto empty trucks. Empty trucks haul coal and dump them into dumps. Coal at dumps is crushed and transported via overland conveyors to be dumped into silos. Coal from silos is pulled via blending conveyors to loadouts. Customer

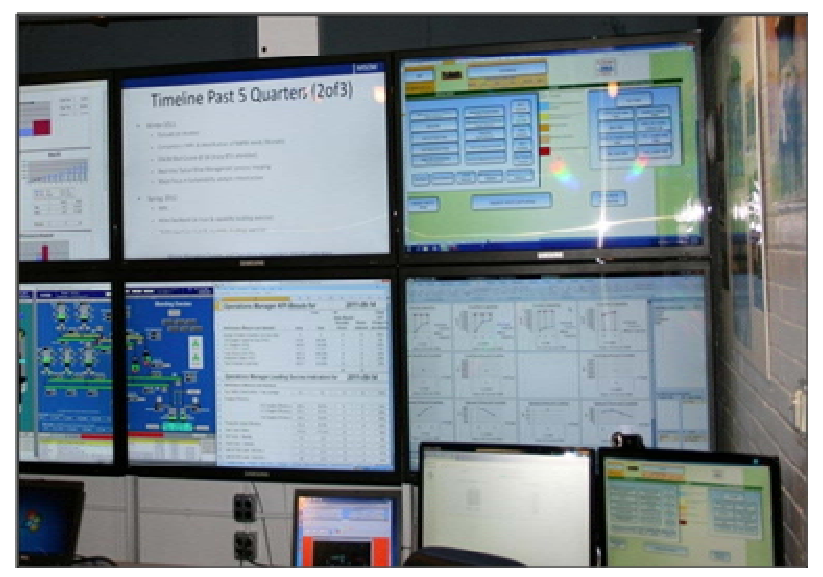

Figure 1: Control room (Nageshwaraniyer et al. 2012).

trains are loaded at these loadouts. Most trucks are of 255 tons capacity. Silos are huge inventories of coal and there are 6 silos in the mine. Five silos are of about 14,000 tons capacity each and the sixth silo is of 50,000 tons capacity (Nageshwaraniyer, Son, and Dessureault 2011). There are two loadouts and they are connected to five silos in the mine via conveyors. The main decision variables during the material handling operations are as follows: 1) truck locks, 2) dump-silo connections and 3) silo blend-set points. Each truck is assigned a shovel and a dump for loading and unloading coal processes respectively. These assignments are called truck locks. Crushed coal from a dump is transported and loaded into a silo specified by dump-silo connection. Silo blend-set points are applied for the five silos of about 14,000 capacity. Coal direction to and from sixth silo can be specified using dump-silo connections. For each silo and loadout combination, a silo blend-set point indicates the percentage out of total capacity of a train, stationed at this loadout, to be filled using coal from the silo under consideration. However, in this paper only truck locks are considered as decision variables for the revenue maximization problem. The main objective of the mine is to maximize revenue obtained from each train. Total revenue is a function of base revenue, premiums and penalties. Premiums and penalties are decided based on customer coal quality specifications and final average quality of coal delivered to a customer train. There are five metrics for 
judging coal quality and they are BTU, Ash, Sodium, Sulfur and Moisture. In general, it is desired by customers to have higher values of average BTU and lower values of averages of other metrics. In addition to revenue from each train, it is also attempted to load trains as fast as possible to maximize revenue obtained in a shift. So, the production rate of coal at the mine is also an important performance objective.

\section{SIMULATION-BASED ROBUST REVENUE MAXIMIZATION}

In this section, the formulation of revenue maximization problem is explained. The objective function in the revenue maximization problem is shown in (1). It is a maximization of a summation of base revenues, premiums and penalties obtained from loading two trains concurrently at the mine. The metamodel obtained from applying RSM to determine the standard deviation in revenue is $y=\beta_{0}+\boldsymbol{\beta}^{\prime} \mathbf{d}+\boldsymbol{\gamma}^{\prime} \mathbf{u}+$ $\mathbf{d}^{\prime} \Delta \mathbf{u}+\varepsilon$. Vectors and matrices are identified in bold. In this expression, $y$ is revenue, $\beta_{0}$ is constant, $\mathbf{d}$ is vector of controllable factors and $\mathbf{u}$ is a vector of uncontrollable factors. $\boldsymbol{\beta}$ and $\boldsymbol{\gamma}$ are first order effects for $\mathbf{d}$ and $\mathbf{u}$, respectively, $\Delta$ is the two factor controllable by uncontrollable two factor interaction matrix and $\varepsilon$ is residual. $\Delta \neq 0$ implies that $\operatorname{Var}(y)$ can be controlled by $\mathbf{d}$. An upper bound on the expression for variance is applied to limit the variability in obtained revenues as shown in (2), where $\mathbf{D}$ is $\operatorname{Cov}(\mathbf{u})$.

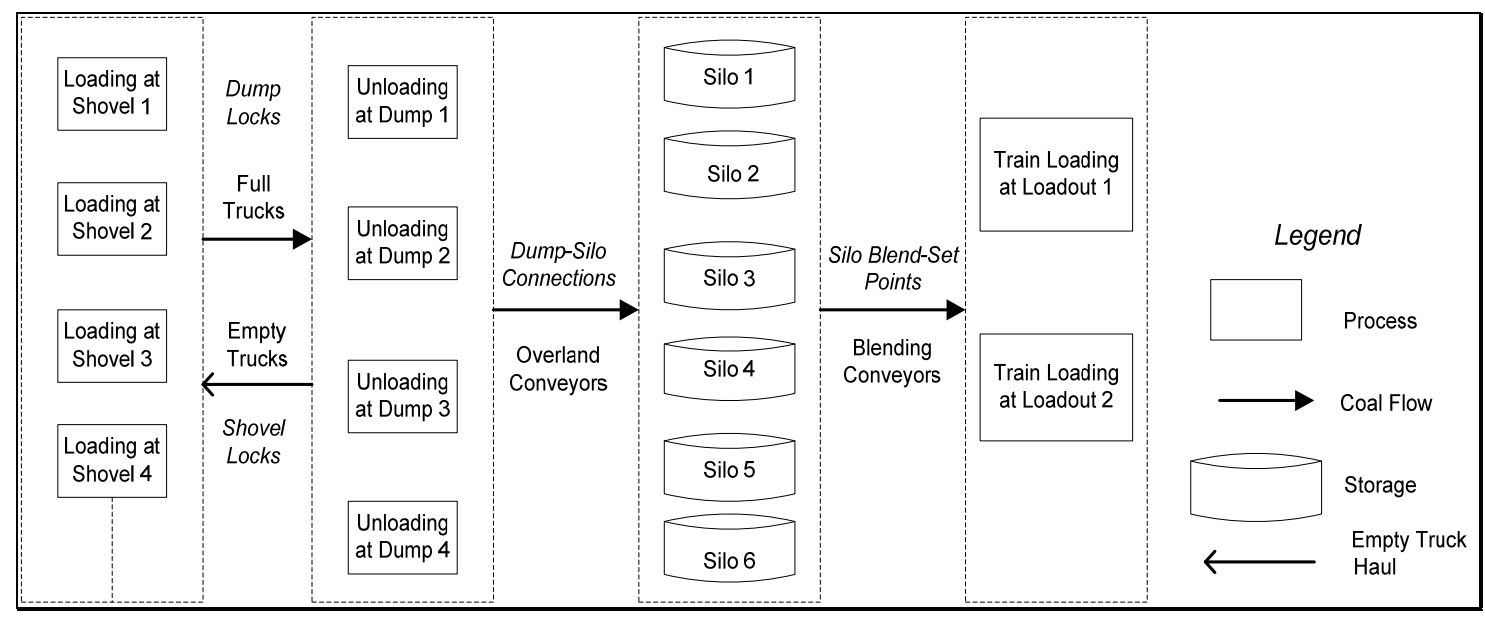

Figure 2: Coal flow in the mine.

The complex expression for tons produced by a shovel and carried by truck and dumped into a train is given in (3) (Table 1). The main use of the simulator is for estimation of this expression for a truck which is a function of its shovel and dump locks, loadtime at the shovel it is assigned to, dumptime at the dump it is assigned to. In addition, other factors affecting it are full haul time, empty haul time, the down event behavior of trucks, shovels and hoppers, dump to silo connections and silo blend-set points. The expression for calculation of average value of a coal quality metric delivered to a train is provided in (4). It is always desired that average quality of delivered BTU be greater than the corresponding rejection limit specified for a particular train, as shown in (5) (Table 2). Also, it is desired to have the average delivered quality of other metrics be lower than their corresponding rejection limits specified for each train, as shown in (6).

In (7) and (8), expressions for calculation of premiums and penalties for five coal quality metrics are provided. Premiums are obtained for BTU if its average delivered value is above the corresponding upper bound. Premiums are obtained for other metrics if their average delivered values are below the corresponding lower bounds. Penalties are obtained for BTU if its average delivered value is below the corresponding lower bound. Penalties are obtained for other metrics if their average delivered values are above the corresponding upper bounds. An expression for calculation of premium with respect to average 


\section{Nageshwaraniyer, Son, and Dessureault}

BTU delivered and penalties with respect to average delivered quality of other metrics is given in (7). Another expression for calculation of penalties with respect to average BTU delivered and premiums with respect to average delivered quality of other metrics is given in (8). In this work, it is assumed that each truck load is split equally among the two trains as shown in (9). This can be achieved by ensuring that silo blend-set points for active silos are set to 50\%. In this way, any amount of coal coming out of a silo is split equally among the two trains. Also, the customer specified premium and penalty limits are same for the two trains as shown in (10). A lower bound on the number of tons produced in an hour of simulation in given in (11). The total amount of tons produced in an hour can be written as twice the amount of coal delivered to each train in the same period. The upper and lower limits for shovel locks and dump locks that is assigned to each truck are given in Equations (12) and (13), respectively.

$$
\begin{aligned}
& \max \mathrm{E}\left[\sum_{i=1}^{2}\left(R_{i}+\sum_{\varphi} P r_{X, i}-\sum_{\varphi} P e_{X, i}\right)\right] \\
& \left(\boldsymbol{\gamma}+\Delta^{\prime} \mathbf{d}\right)^{\prime} \mathbf{D}\left(\boldsymbol{\gamma}+\Delta^{\prime} \mathbf{d}\right)+\sigma_{\varepsilon}^{2} \leq U \\
& \text { NTrucks }_{j} \\
& \text { Tons }_{k, i}^{l}=f\left(\bigcup_{l=1}\left\{S L^{l}, D L^{l}, \text { fullhaultime }_{l}, \text { emptyhaultime }_{l}\right\}, \text { loadtime }_{k}, \text { dumptime }_{m},\right. \\
& M T B F_{k}, M T B F_{l}, M T B F_{m}, M T T R_{k}, M T T R_{l}, M T T R_{m}, \text { Dump - siloconnections, Siloblendsetpoints); } \\
& \operatorname{del}_{X, i}=\frac{\sum_{k=1}^{\text {NShovels }_{j}}\left(\sum_{j=1}^{\text {NTrucks }_{j}} \text { Tons }_{k, i}^{l}\right) * X_{k}}{\sum_{k=1}^{\text {NShovels }_{j}}\left(\sum_{j=1}^{N \text { NTucks }_{j}} \text { Tons }_{k, i}^{l}\right)}, \forall X \in \varphi, \forall i ; \\
& \operatorname{del}_{X, i} \geq \operatorname{rej}_{X, i}, \quad X=B T U, \forall i \\
& \operatorname{del}_{X, i} \leq r e j_{X, i}, \quad\{X \in \varphi: X \neq B T U\}, \forall i ; \\
& Y_{X, i}=C\left(\frac{\operatorname{del}_{X, i}}{\text { requpper }_{X, i}}-1\right), \text { if }\left((Y, X, C)=\left(\operatorname{Pr}, B T U, C_{1}\right) \text { or }\left(P e,\{X \in \varphi: X \neq B T U\}, C_{2}\right)\right) \\
& \text { and if }\left(\operatorname{del}_{X, i} \geq \text { requpper }_{X, i}\right) \text {, else } 0 \text {; } \\
& Y_{X, i}=C\left(1-\frac{\text { del }_{X, i}}{\text { reqlower }_{X, i}}\right), \\
& \text { if }\left((Y, X, C)=\left(P e, B T U, C_{2}\right) \text { or }\left(\operatorname{Pr},\{X \in \varphi: X \neq B T U\}, C_{1}\right)\right) \\
& \text { and if }\left(\text { del }_{X, i} \leq \text { reqlower }_{X, i}\right) \text {, else } 0 \text {; } \\
& \text { Tons }_{k, 1}^{l}=\text { Tons }_{k, 2}^{l}, \forall k=1 \ldots \text { NShovel }_{j}, \forall l=1 \ldots \text { NTrucks } s_{j} ; \\
& \left\{\text { requpper }_{X, 1}\right\}=\left\{\text { requpper }_{X, 2}\right\},\left\{\text { reqlower }_{X, 2}\right\}=\left\{\text { reqlower }_{X, 2}\right\}, \forall X \in \varphi \text {; } \\
& 2 * \sum_{k=1}^{\text {NShovels }_{j}} \sum_{j=1}^{\text {NTrucks }_{j}} \text { Tons }_{k, 1}^{l} \geq L ; \\
& 1 \leq S L^{l} \leq \text { NShovels }_{j} ; \\
& 1 \leq D L^{l} \leq 4 \text {. }
\end{aligned}
$$

\section{EXPERIMENTS}

\subsection{Configuration}

For the experiments the configuration used is as follows :1) a desktop with 8 GB RAM, 1 TB hard drive and 64-bit Windows 7 Operating System. 2) Arena 13.9 and SQL Server Management Studio 2008 installed. 3) Access to Windows Server 2008 at The University of Arizona containing a copy of the real data from data warehouse located remotely at the mine. 
Nageshwaraniyer, Son, and Dessureault

Table 1: Table of simulation outputs and decision variables.

\begin{tabular}{|c|l|c|c|}
\hline Simulation Output & \multicolumn{2}{|c|}{ Definition } \\
\hline $\operatorname{Tons}_{k, i}^{l}:$ & Actual amount of tons loaded from shovel $\mathrm{k}$ by truck 1 and dumped for delivering to train i \\
\hline$d e l_{X, i}$ & $\begin{array}{l}\text { Weighted average of metric X of coal quality delivered to train i where } \mathrm{X}=\mathrm{BTU}, \\
\text { Ash, Sodium, Sulfur or Moisture }\end{array}$ \\
\hline $\begin{array}{c}\text { Decision } \\
\text { Variable }\end{array}$ & \multicolumn{1}{|c|}{ Definition } & Decision Variable & \multicolumn{1}{|c|}{ Definition } \\
\hline$S L^{l}:$ & $\begin{array}{l}\text { shovellock: the shovel to which truck } 1 \text { is } \\
\text { locked }\end{array}$ & $D L^{l}:$ & $\begin{array}{l}\text { dumplock : the dump to which truck } 1 \\
\text { is locked }\end{array}$ \\
\hline
\end{tabular}

Table 2: Table of simulation inputs.

\begin{tabular}{|c|c|c|c|}
\hline $\begin{array}{l}\text { Simulation } \\
\text { Input }\end{array}$ & Definition & $\begin{array}{l}\text { Simulation } \\
\text { Input }\end{array}$ & Definition \\
\hline$N_{j}:$ & Number of trains in shift $j$ & NShovels $s_{j}$ & Number of active shovels in shift $j$ \\
\hline $\begin{array}{l}M T B F_{k}, M T B F_{l}, \\
\quad M T B F_{m}:\end{array}$ & $\begin{array}{l}\text { Mean time between failures for shovel } \mathrm{k}, \\
\text { truck } 1 \text {, dump } \mathrm{m} \text { respectively }\end{array}$ & $\begin{array}{l}\operatorname{MTTR}_{k}, \text { MTTR }_{l} \\
\quad \operatorname{MTTR}_{m}:\end{array}$ & $\begin{array}{l}\text { Mean time to repair for shovel } \mathrm{k} \text {, truck } 1 \text {, dump } \mathrm{m} \\
\text { respectively }\end{array}$ \\
\hline$L:$ & $\begin{array}{l}\text { Lower bound for tons produced in each } \\
\text { hour of whole simulation }\end{array}$ & $U:$ & Upper bound for variance in revenue \\
\hline$X_{k}:$ & $\begin{array}{l}\text { Value of metric } X \text { of coal quality from } \\
\text { shovel } k \text { where } X=B T U \text {, Ash or Sodium }\end{array}$ & $r e j_{X, i}:$ & $\begin{array}{l}\text { Weighted average of metric } \mathrm{X} \text { of coal quality that is } \\
\text { a limit for rejection of train } \mathrm{i} \text { where } \mathrm{X}=\mathrm{BTU} \text {, } \\
\text { Ash, Sodium, Sulfur or Moisture }\end{array}$ \\
\hline$R_{i}:$ & $\begin{array}{l}\text { Base revenue in dollars obtained from load- } \\
\text { ing train i }\end{array}$ & NTrucks $_{j}$ : & Number of active trucks in shift $\mathrm{j}$ \\
\hline $\operatorname{Pr}_{X, i}:$ & $\begin{array}{l}\text { Premium in dollars obtained from train i on } \\
\text { metric X of coal quality where } \mathrm{X}=\mathrm{BTU}, \\
\text { Ash, Sodium, Sulfur or Moisture }\end{array}$ & reqlower $_{X, i}:$ & $\begin{array}{l}\text { Lower bound value of metric } \mathrm{X} \text { of coal quality re- } \\
\text { quired by train i where } \mathrm{X}=\mathrm{BTU} \text {, } \\
\text { Ash, Sodium, Sulfur or Moisture }\end{array}$ \\
\hline$P e_{X, i}:$ & $\begin{array}{l}\text { Penalty in dollars incurred from train } \mathrm{i} \text { on } \\
\text { metric X of coal quality where } \mathrm{X}=\mathrm{BTU}, \\
\text { Ash, Sodium, Sulfur or Moisture }\end{array}$ & requpper $_{X, i}$ : & $\begin{array}{l}\text { Upper bound value of metric } \mathrm{X} \text { of coal quality re- } \\
\text { quired by train i where } \mathrm{X}=\mathrm{BTU} \text {, } \\
\text { Ash, Sodium, Sulfur or Moisture }\end{array}$ \\
\hline$C_{1}, C_{2}:$ & Constants & $\varphi:$ & $\{B T U$, Ash, Sodium, Sulfur, Moisture $\}$ \\
\hline $\begin{array}{l}\text { Dump } \\
\text { - siloconne } \\
\text { ctions: }\end{array}$ & Set of connections from dumps to a silos & $\begin{array}{l}\text { Siloblend } \\
\text { setpoints: }\end{array}$ & Set of connections from silos to each loadout \\
\hline loadtime $_{k}:$ & Loading time in secs per truck at shovel $\mathrm{k}$. & dumptime $_{m}:$ & Dumping time in secs per truck at dump $\mathrm{m}$ \\
\hline fullhaultime : & $\begin{array}{l}\text { Time for loaded truck } 1 \text { at shovel to reach } \\
\text { dump }\end{array}$ & emptyhaultime : & Time for empty truck 1 at dump to reach shovel \\
\hline
\end{tabular}

In this paragraph, the real data warehouse at the mine is briefly described. The whole warehouse consists of the following main components: sensors, equipment, a production SQL server, an intermediate SQL server, a number of SSIS (SQL Server Integration Services) packages (Figure 3). Sensors on different equipment such as shovels, trucks, hoppers, conveyors, silos and loadouts transmit real-time information to production servers. These raw data are stored for different equipment separately in tables. The raw data is cleaned and transformed using SSIS packages to be stored in an intermediate server. The data in the intermediate server is still not in user-friendly format. So, a set of TSQL (Transact-SQL) stored procedures are used to further clean and transform the data in intermediate servers to be used by the User Interface (Figure 4) and Simulator (Figure 5). The user can specify either historical or current datetime as a parameter to the stored procedures. Based on this parameter, the corresponding data is extracted from different databases in the intermediate server, cleaned and then transformed to be displayed via pivot tables in the User Interface. There are currently 13 different sheets in which the data from different equipment is stored (Figure 3). The different blocks used to model shovel and dumps part of the Simulator in Arena, which are of focus in this paper is shown in Figure 4. 


\section{Nageshwaraniyer, Son, and Dessureault}

There is an additional exe file that comes as a part of the User Interace and Simulator package that can be used to generate a simulation model of surface coal mines whose structure is similar to the mine under case study. The exe file is based on data-driven modeling framework that contains a UML-based (Unified Modeling Language) information model to store mine structural, simulation input and simulation output information. For more information the reader is referred to Meng et al. (2013).

Input distributions of uncontrollable factors have been calculated using Input Analyser. Input Analyser is another add-on that comes with Arena to fit statistical distributions to input data, which can be later fed into Arena blocks and elements. The distribution fitting procedure was carried out in an offline manner. First, data was retrieved over a period of an year for the different uncontrollable factors and separated for individual equipment. For truck haul times, shovel loading times and dumping times the distributions were separately calculated for each individual truck, shovel and dumps respectively. This is based on the assumption that distributions of these parameters are univariate. Also, loading and dumping times are dependent on shovel and dump properties respectively.

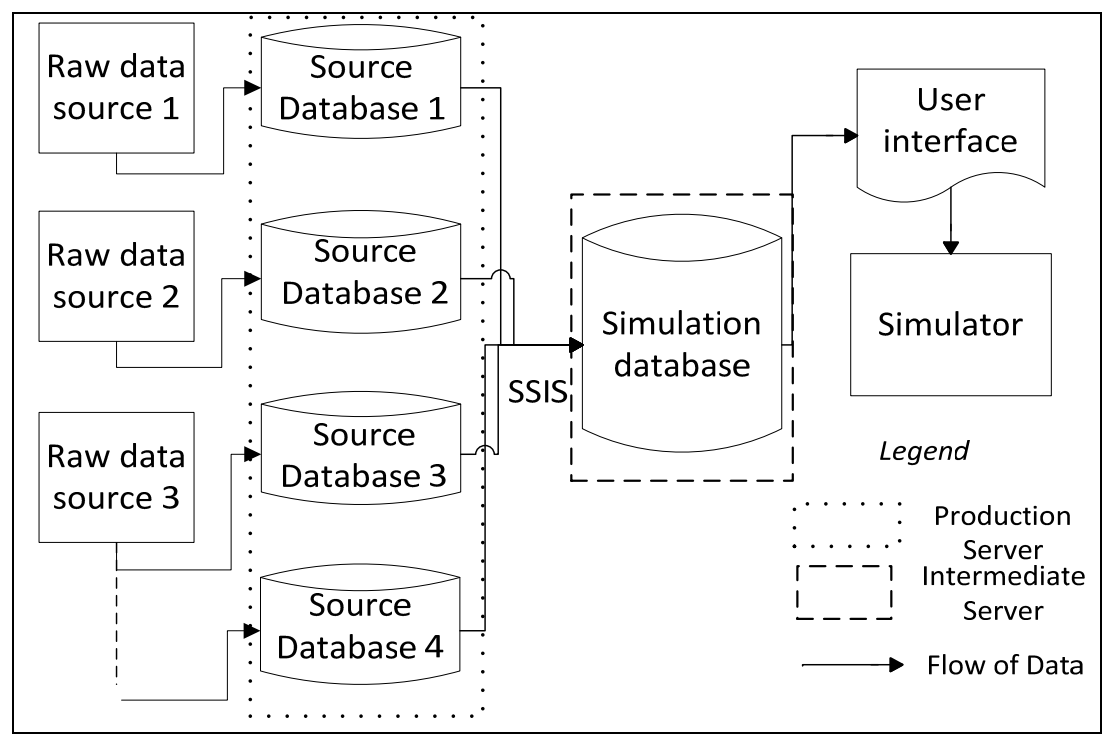

Figure 3: Data flow from data warehouse at mine to simulator and user interface (Nageshwaraniyer, Son, and Dessureault 2013b).

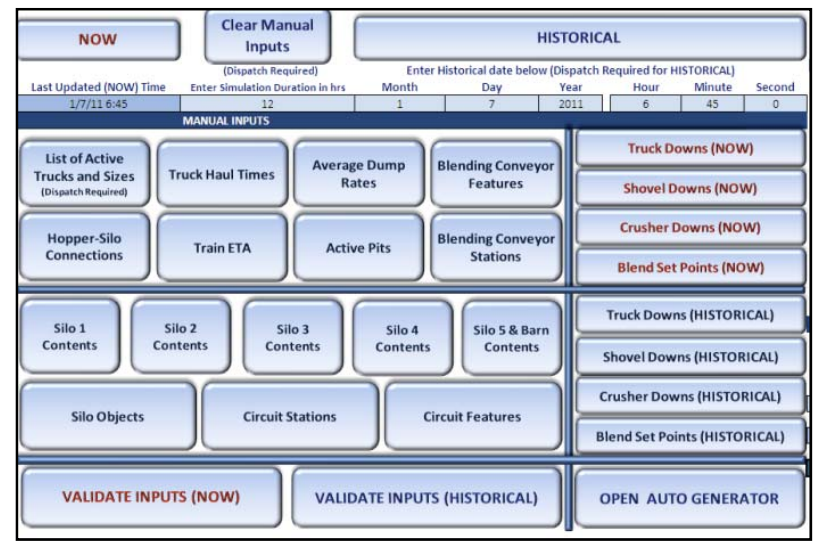

Figure 4: User interface in

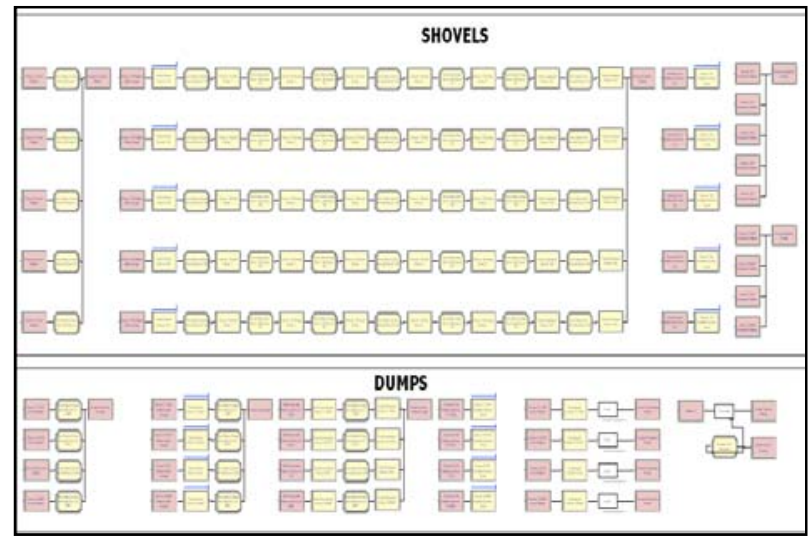

Figure 5: Simulator in Arena.

MS Excel (Nageshwaraniyer, Son, and Dessureault 2013b). 


\subsection{Results}

Three types of experiments were conducted in this paper. They are as follows: 1) Determining the amount of tons delivered at dumps by varying the number of available trucks. 2) Determining the amount of tons delivered at dumps by varying the total number of down events. 3) Confidence Interval half-width of the amount of tons delivered at dumps when the number of trucks are kept to a low number. These experiments have been performed by taking the data at the beginning of a shift. Also, decision variable plus other parameter setting having the same expected value are plotted in the same graph. For all the experiments, the number of available shovels was fixed at 6 and number of available dumps was fixed at 4 . The number of replications used was fixed at 20.

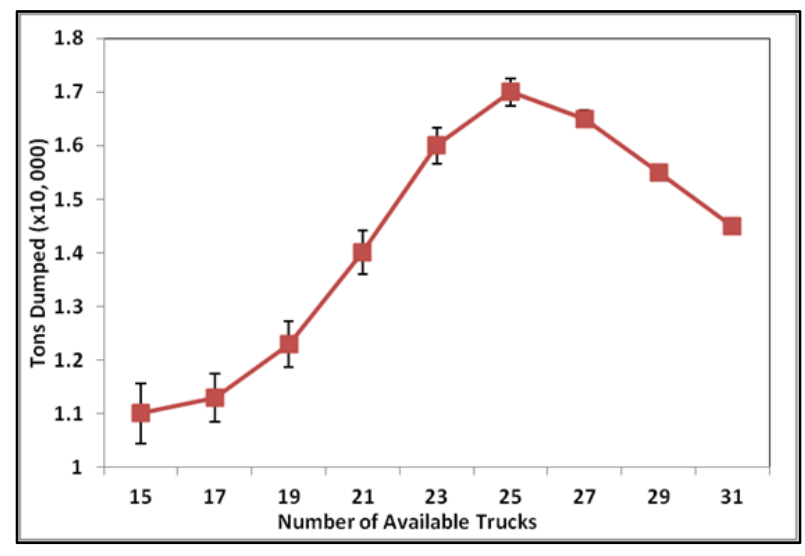

Figure 6: Increase in number of trucks vs tons Produced.

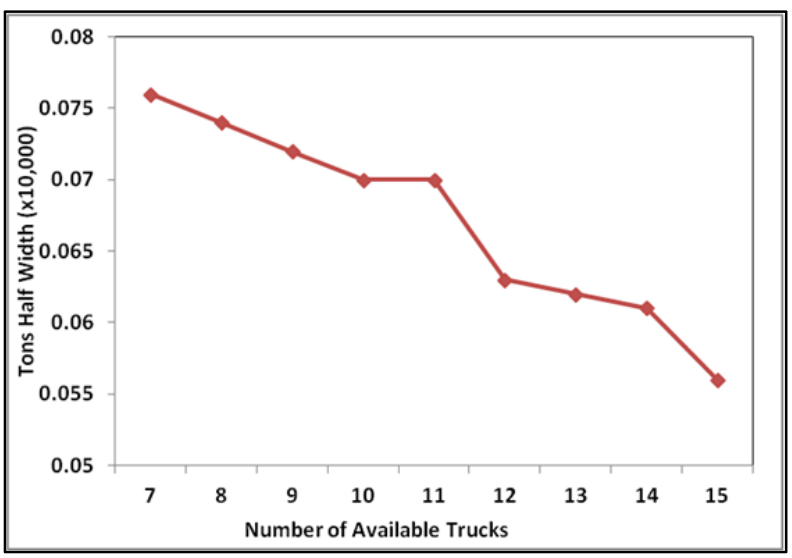

Figure 8: Trucks available vs. the variability in tons produced.

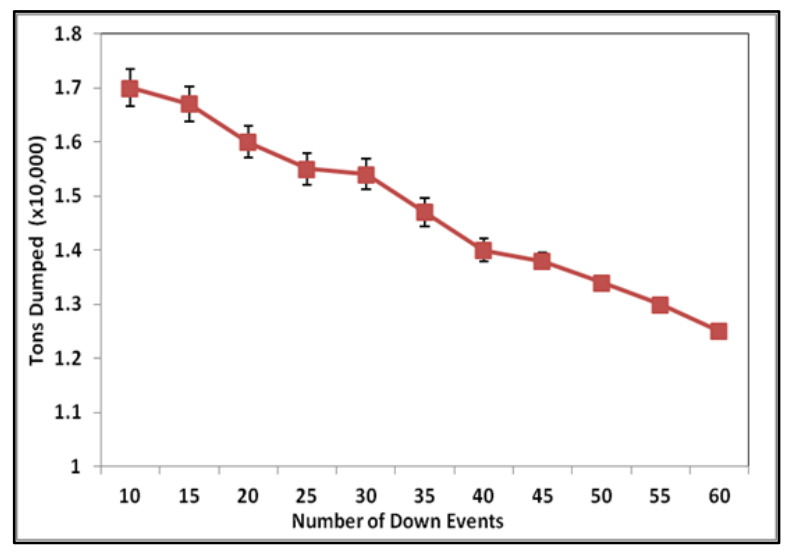

Figure 7: Increase in number of total down events vs. tons produced.

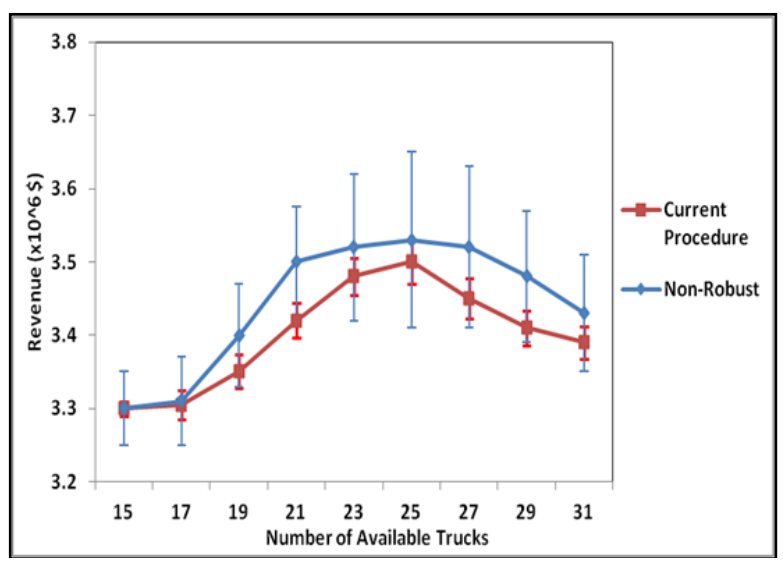

Figure 9: Current procedure vs. OptQuest.

In general, it is desired that larger of tons be delivered in each hour of the shift as to be able to load more trains, while keeping the revenue derived from loading at the same or higher. The total number of down events for all equipment was fixed at 10 for the hour. In the first experiment, it can be seen that when the number of available trucks are progressively increased the confidence interval width of the amount of tons delivered is decreased (see Figure 6). So, it is possible to fit an output distribution to the amount of tons delivered at dumps when the number of trucks are at a higher value. Such a distribution can be uni- 


\section{Nageshwaraniyer, Son, and Dessureault}

variate for this experiment and based on single discrete variable of number of trucks for this experiment. From the result, it can also be seen that the amount of tons delivered becomes more predictable when the number of trucks are increased.

In the second experiment, the total number of down events for shovels, trucks and dumps are collectively referred to as down events (see Figure 7). The number of trucks are fixed at 23. The number of down events are increased progressively as shown in the Figure. With an increase in the total number of down events, it can be seen that the confidence interval width of the amount of tons delivered at dumps in an hour is decreased. From this result, it can be seen that similar to the first experiment, it is possible to fit an output distribution to the amount of tons delivered at dumps when the number of down events are at a higher value. And it can be a univariate distribution based on single variable of number of down events for this experiment. And similar to previous experiment, it can be observed from this result that the amount of tons delivered becomes predictable when the number of down events are increased.

In the third experiment, it was desired to observe how the confidence interval half-width behaved when the number of available trucks at the start of the simulation was low (see Figure 8). The number of down events was fixed at 10 . With increase in number of trucks, the standard deviation of amount of tons delivered in an hour at the dumps is decreased. It is implied that when lower number of trucks (such as 7 or 8 ) are used the outputs become harder to estimate. In Figure 9, a comparison between current procedure and OptQuest has been drawn for different number of available trucks as settings. For each setting it can be seen that the current procedure helps obtain narrower confidence intervals for revenue when compared with OptQuest, which is indicated as "Non-Robust" in the figure.

\section{CONCLUSION}

In this paper, a simulation-based robust optimization method is proposed for revenue maximization of surface coal mines around the world. Towards that end, one of the largest coal mines in North America is taken as case study. A large simulation model is constructed in Arena that is run using real production data available from the mine. In this work, the system of focus is truck-shovel-dumps in the mine. Truck locks are considered as decision variables for the optimization problem. RSM is used to estimate the expression for the variance of the revenue under different simulation model parameter settings. This expression is then applied as constraint in OptQuest to maximize expected value of revenue while minimizing variance. Experiments are conducted by varying the number of available trucks and down events in the time that the trains are getting loaded. Model parameter settings resulting in the same expected value are plotted in the same graph. It can be observed from the results that the proposed procedure can help determine the setting of trucks down events for which the tons produced can be precisely estimated. Also, large number of trucks and down events reduce the variability in the production. It is left to the decision makers at the mine to choose decision variables to balance maximize expected value of revenue, with the corresponding variance.

Future work involves comparison of results after applying the current approach, with historically obtained revenues. It will be attempted to obtain decision variable settings that not only result in higher expected value of revenues but also are relatively more robust against the uncontrollable factors.

\section{ACKNOWLEDGMENTS}

This work has been supported by Science Foundation of Arizona.

\section{REFERENCES}

Barton, R. R., and M. Meckesheimer. 2006. "Metamodel-based Simulation Optimization." In Handbooks in operations research and management science: Simulation, Edited by S.G. Henderson and B.L. Nelson, 535-574. New York: Elsevier Science. 
Bertsimas, D. 2011. "Theory and Applications of Robust Optimization." SIAM REVIEW 53:464-501.

Dellino, G., J.P.C. Kleijnen, and C. Meloni. 2009. "Robust Simulation-Optimization using Metamodels." In Proceedings of the 2009 Winter Simulation Conference, Edited by J M. D. Rossetti, R. R. Hill, B. Johansson, A. Dunkin, and R. G. Ingalls, 540-550. Piscataway, New Jersey: Institute of Electrical and Electronics Engineers, Inc.

Dellino, G., J.P.C. Kleijnen, and C. Meloni. 2010. "Robust Optimization in Simulation: Taguchi and Response Surface Methodology." International Journal of Production Economics 125:52-59.

Dellino, G., J.P.C. Kleijnen, and C. Meloni. 2012. "Robust Optimization in Simulation: Taguchi and Krige Combined." INFORMS Journal on Computing 24:471-484.

Fu, M. 2002. "Optimization for Simulation: Theory vs. Practice." INFORMS Journal on Computing 14:192-215.

Meng, C., S.S. Nageshwaraniyer, A. Maghsoudi, Y. Son, and S. Dessureault. 2013. "Data-driven Modeling and Simulation Framework for Material Handling Systems in Coal Mines." Computers \& Industrial Engineering 64: 766-779.

Nageshwaraniyer, S.S., Y. Son, and S. Dessureault. 2011. "Simulation-based Optimal Planning for Material Handling Network in Mining." In Proceedings of the 2011 Industrial Engineering Research Conference, Edited by T. Doolen and E. Van Aken.

Nageshwaraniyer, S.S., C. Meng, A. Maghsoudi, Y. Son, and S. Dessureault. 2012. "Simulation-based Decision Support System for Sustainable Coalmining Operations." In Proceedings of the 2012 Industrial Engineering Research Conference, Edited by G. Lim and J.W. Herrmann.

Nageshwaraniyer, S.S., Y. Son, and S. Dessureault. 2013a. "Simulation Based Optimal Planning for Material Handling Network in Mining." SIMULATION: Transactions of The Society for Modeling and Simulation International 89:330-345.

Nageshwaraniyer, S.S., Y. Son, and S. Dessureault. 2013b. "Simulation-based Parallel Direct Search Optimization for Revenue Maximization of Coalmines." Accepted in Proceedings of the 2013 Industrial and Systems Engineering Research Conference, Edited by A. Krishnamurthy and W.K.V. Chan, eds.

Neddermeijer, H.G., G.J. van Oortmarssen, N. Piersma, R. Dekker. 2000. "A Framework for Response Surface Methodology for Simulation Optimization." In Proceedings of the 2000 Winter Simulation Conference, Edited by J.A. Joines, R.R. Barton, K. Kang, and P.A. Fishwick, 129-136. Piscataway, New Jersey: Institute of Electrical and Electronics Engineers, Inc.

Ramberg, J.S., S.M. Sanchez, P.J. Sanchez, L.J. Hollick. 1991. "Designing Simulation Experiments: Taguchi Methods and Response Surface Metamodels." In Proceedings of the 1991 Winter Simulation Conference, Edited by B.L. Nelson, W.D. Kelton, and G.M. Clark, 167- 176. Piscataway, New Jersey: Institute of Electrical and Electronics Engineers, Inc.

Sahinidis, N. 2004. "Optimization under Uncertainty: State-of-the-art and Opportunities." Computers and Chemical Engineering 28:971-983.

Smart Simulation Blog. 2012. "Simulation is the Best Way to Allocate Trucks to Shovels in Open-pit Mine Operations." Accessed April $14 \quad 2013 . \quad$ http://smart-simulationblog.blogspot.com/2012/06/simulation-is-best-way-to-allocate.html.

U.S. Energy Information Administration. 2012. “AEO2013 Early Release Overview.” Accessed April 14 2013. http://www.eia.gov/forecasts/aeo/er/early_production.cfm.

\section{AUTHOR BIOGRAPHIES}

SAI SRINIVAS NAGESHWARANIYER is a Ph.D. student in the Department of Systems and Industrial Engineering at The University of Arizona. His research interests are in the areas of Coal mining and transport logistics, Distributed simulations of complex systems, and Meta-heuristics. He is a member of IIE and INFORMS. He received the IIE Graduate Research Award in 2012. He can be reached at nageshwa@email.arizona.edu. 
YOUNG-JUN SON is Professor of Systems and Industrial Engineering and Director of Advanced Integration of Manufacturing Systems and Technologies Center at The University of Arizona. His research focuses on the coordination of a multi-scale, networked-federated simulation and decision model needed for design and control in extended manufacturing enterprise, water-environment-energy nexus, homeland security, and social network. He has received several research awards such as the SME 2004 Outstanding Young Manufacturing Engineer Award, the IIE 2005 Outstanding Young Industrial Engineer Award, the IERC Conference Best Paper Awards (2005, 2008, 2009), and Best Paper of the Year Award in 2007 from IJIE. He can be reached at son@sie.arizona.edu.

SEAN DESSUREAULT is an Associate Professor at The University of Arizona's Mining and Geological Engineering department where he directs the Mining Intelligence Research Laboratory (MIRG) Laboratory, which has a remote operations control room and development facilities where applied research and pre-commercial products are developed. His consulting company MISOM Consulting Services Inc., designs, builds, and services data warehouses and advises corporate leadership on technology strategy. He also pursues sustainable development research and consulting related to political risk, web mining, and sustainable development indicators. He can be reached at sdessure@email.arizona.edu. 